Departments of

Comparative Genomics ${ }^{1}$, Discovery Genetics², Genomics Bioinformatics 3 , Microbial Bioinformatics and Microbial Genetics ${ }^{4}$, Glaxo SmithKline, King of Prussia, PA 19406, USA

\section{The ARO4 gene of Candida albicans encodes a tyrosine-sensitive DAHP synthase: evolution, functional conservation and phenotype of Aro3p-, Aro4p-deficient mutants}

\author{
Silvino Sousa, ${ }^{1}$ Megan M. McLaughlin, ${ }^{1}$ Sarita A. Pereira, ${ }^{1} \dagger$ \\ Stephanie VanHorn, ${ }^{2}$ Robert Knowlton, ${ }^{3}$ James R. Brown, ${ }^{4}$ \\ Richard O. Nicholas ${ }^{4}$ and George P. Livi ${ }^{1}$
} Author for correspondence: George P. Livi. Tel: +1 610270 7717. Fax: +1 6102707962.
e-mail: george_p_livi@gsk.com

The enzyme 3-deoxy-D-arabinoheptulosonate-7-phosphate (DAHP) synthase catalyses the first step in aromatic amino acid biosynthesis in prokaryotes, plants and fungi. Cells of Saccharomyces cerevisiae contain two catalytically redundant DAHP synthases, encoded by the genes ARO3 and ARO4, whose activities are feedback-inhibited by phenylalanine and tyrosine, respectively. AR03/4 gene transcription is controlled by GCN4. The authors previously cloned an ARO3 gene orthologue from Candida albicans and found that: (1) it can complement an aro3 aro4 double mutation in S. cerevisiae, an effect inhibited by excess phenylalanine, and (2) a homozygous aro3-deletion mutant of $C$. albicans is phenotypically $\mathrm{Aro}^{+}$, suggesting the existence of another isozyme(s). They now report the identification and functional characterization of the C. albicans orthologue of S. cerevisiae Aro4p. The two Aro4p enzymes share $68 \%$ amino acid identity. Phylogenetic analysis places the fungal DAHP synthases in a cluster separate from prokaryotic orthologues and suggests that $A R O 3$ and $A R O 4$ arose from a single gene via a gene duplication event early in fungal evolution. C. albicans ARO4 mRNA is elevated upon amino acid starvation, consistent with the presence of three putative Gcn4p-responsive elements (GCREs) in the gene promoter sequence. C. albicans ARO4 complements an aro3 aro4 double mutation in S. cerevisiae, an effect inhibited by excess tyrosine. The authors engineered $\triangle a r 03 / \Delta$ aro3 $\triangle$ aro4/MET3p::ARO4 cells of C. albicans (with one wild-type copy of ARO4 placed under control of the repressible MET3 promoter) and found that they fail to grow in the absence of aromatic amino acids when ARO4 expression is repressed, and that this growth defect can be partially rescued by aromatic amino acids and certain aromatic amino acid pathway intermediates. It is concluded that, like $S$. cerevisiae, $C$. albicans contains two DAHP synthases required for the first step in the aromatic amino acid biosynthetic pathway.

Keywords: aromatic amino acids, GCN4, MET3 promoter, pathogenic fungi

\section{INTRODUCTION}

The primary step in aromatic amino acid biosynthesis involves the enzyme 3-deoxy-D-arabinoheptulosonate- 7-phosphate (DAHP) synthase. This enzyme catalyses the condensation of erythrose 4-phosphate and phosphoenolpyruvate to form 3-deoxy-D-arabinoheptulosonate7-phosphate. This step is followed by a series of

†Present address: AstraZeneca Pharmaceuticals LP, 725 Chesterbrook Blvd, Building C-2E08A, Wayne, PA 19087-5677, USA.

Abbreviations: 3AT, 3-aminotriazole; DAHP, 3-deoxy-D-arabinoheptulosonate 7-phosphate; 5-FOA, 5-fluoroorotic acid; GCRE, Gcn4p-responsive element; SC, synthetic complete; UTR, untranslated region.

The GenBank accession number for the sequence reported in this paper is U53216. 
reactions leading to the production of chorismic acid, which serves as a branchpoint compound for two separate pathways resulting in the production of phenylalanine/tyrosine and tryptophan (reviewed by Hinnebusch, 1990; Bently, 1990; Braus, 1991). Thus, DAHP synthases play a key role in catalysing the first committed step of the aromatic amino acid pathway, and as a consequence, cellular enzymes are tightly regulated.

Cells of the yeast Saccharomyces cerevisiae contain two isozymes of DAHP synthase encoded by the genes ARO3 and ARO4 (Teshiba et al., 1986; Paravicini et al., 1988, 1989; Kunzler et al., 1992). Transcription of both genes is coordinately controlled by Gen4p, which binds to Gcn $4 p$-responsive elements (GCREs) in the promoters. Enzyme activity is also regulated at the posttranslational level, i.e. the activity of Aro3p is feedbackinhibited by phenylalanine, whereas Aro4p is inhibited by tyrosine (Hinnebusch, 1990; Braus, 1991). Many prokaryotes possess a third DAHP synthase whose activity is inhibited by tryptophan. Existence of a third isozyme has also been reported in the fungus Neurospora crassa, although the corresponding gene has not been identified (Nimmo \& Coggins, 1981).

We are studying the nature and complexity of DAHP synthases in the pathogenic fungi as potential antifungal drug targets, since: (1) humans lack a comparable biosynthetic pathway - instead they rely on dietary sources for phenylalanine and tryptophan, and can only synthesize tyrosine via hydroxylation of phenylalanine; (2) based on pathogenicity studies of other auxotrophic mutants of Candida albicans and Cryptococcus neoformans (Manning et al., 1984; Shepherd, 1985; Kirsch \& Whitney, 1991; Perfect et al., 1993), aromatic amino acid auxotrophs are predicted to display decreased virulence in vivo as a result of poor growth due to suboptimal amino acid bioavailability; and (3) certain amino acid biosynthesis inhibitors have been used safely and effectively as herbicides (reviewed by Kishore \& Shah, 1988).

We previously cloned an ARO3 gene orthologue from the diploid pathogenic fungus C. albicans and found that it can complement an aro3 aro 4 double mutation in $S$. cerevisiae, and that complementation is inhibited by excess phenylalanine (Pereira \& Livi, 1993). Expression of C. albicans ARO3 mRNA is induced in response to amino acid starvation, consistent with the presence of two putative GCREs in the promoter sequence (Pereira \& Livi, 1995). A homozygous aro3-deletion mutant strain was constructed and found to be prototrophic $\left(\mathrm{Aro}^{+}\right)$on synthetic complete media lacking aromatic amino acids (Pereira \& Livi, 1996), suggesting the existence of at least one additional isozyme. A small genomic DNA fragment was PCR-amplified from the mutant strain using degenerate primers, and its nucleotide sequence was found to predict a DAHP-synthaserelated peptide with a strong homology to $S$. cerevisiae Aro4p (Pereira \& Livi, 1996). In this study, we have cloned the complete gene defined by this DNA fragment and determined its evolutionary relationship to known DAHP synthases. We have evaluated its expression in response to nutrient deprivation and the effect of feedback inhibition on its gene product. In addition, we have created strains of C. albicans deficient in Aro3p and Aro4p, and show that they display a conditional growth phenotype in vitro, indicating the presence of only two DAHP synthases.

\section{METHODS}

Strains and growth conditions. Synthetic complete (SC) liquid and agar media and dropout derivatives thereof were prepared according to Hicks \& Herskowitz (1976), with the addition of $1 \mu \mathrm{g} \mathrm{ml}^{-1}$ each of thiamin and biotin. Cells of C. albicans strain B311-A were prepared for Northern blot analysis by shaking at $30{ }^{\circ} \mathrm{C}$ to mid-exponential phase $\left(10^{7}\right.$ cells $\left.\mathrm{ml}^{-1}\right)$ in SC liquid medium supplemented with $1 \mu \mathrm{g} \mathrm{ml}^{-1}$ of both thiamin and biotin. Cultures were split into two: 3aminotriazole (3AT) was added to one culture to a final concentration of $10 \mathrm{mM}$, and cultures were incubated for $6 \mathrm{~h}$ to allow for induction of the starvation response. Cells of $S$. cerevisiae were prepared for functional expression studies by growing to mid-exponential phase $\left(\mathrm{OD}_{540} 1\right)$ in SC-Leu liquid medium. These were then washed twice in sterile distilled water, and $15 \mu \mathrm{l}$ of each culture was spotted onto each appropriate plate. Plates were incubated at $30{ }^{\circ} \mathrm{C}$ for $24 \mathrm{~h}$. The same $S$. cerevisiae strains used for feedback regulation studies were prepared as above except that the cells were washed twice in either SC-Leu, SC-Leu-Tyr-Trp $+5 \mathrm{mM}$ Phe or SC-Leu-Phe-Trp $+5 \mathrm{mM}$ Tyr before being resuspended in an equal volume of each of these media and spotted onto the appropriate plates. Feedback-inhibition studies in C. albicans were performed by growing the indicated strains in SC medium to $\mathrm{OD}_{600} 1 \cdot 0$, washing with sterile water and then resuspending in an equal volume of either SC, SC lacking aromatic amino acids or SC lacking aromatic amino acids to which excess $(5 \mathrm{mM})$ tyrosine or phenylalanine had been added. Cultures were grown at $30^{\circ} \mathrm{C}$ with shaking for $2 \mathrm{~h}$ then diluted to $\mathrm{OD}_{600} 0 \cdot 1,0.01$ and 0.001 in the same media and spotted $(15 \mu \mathrm{l})$ onto plates containing the corresponding media. Plates were incubated for $16 \mathrm{~h}$ at $30^{\circ} \mathrm{C}$. Strains used in the $M E T 3$ promoter repression assay were pregrown for $4 \mathrm{~h}$ in SC liquid medium with or without aromatic amino acids and with or without $2.5 \mathrm{mM}$ cysteine and methionine. Cell densities were adjusted to $\mathrm{OD}_{600} 0 \cdot 1$ in the appropriate media, 10 -fold serial dilutions were spotted $(15 \mu \mathrm{l})$ onto agar plates containing each medium, and plates were incubated for $16 \mathrm{~h}$ at $30{ }^{\circ} \mathrm{C}$.

Cloning the ARO4 gene. Pereira \& Livi (1996) previously described using degenerate PCR primers to amplify a $222 \mathrm{bp}$ DNA fragment encoding a DAHP-synthase-related peptide from C. albicans strain SPC64, a homozygous $\triangle$ aro3 mutant. This DNA fragment was labelled and used as a probe to screen a C. albicans strain B792-derived YEp13-based genomic library carried in Escherichia coli (Rosenbluh et al., 1985). Hybridizations and stringency washes were carried out using the Rapid Hyb system (Amersham Life Sciences) according to the manufacturer's protocol.

Phylogenetic analyses. Publicly available databases, including partial genomic sequences, were searched for homologous ORFs to class I DAHP synthases from S. cerevisiae (Aro3p and Aro4p) and E. coli (AroF, AroG, and AroH) using the programs BLASTP, TBLASTN (Altschul et al., 1990) and PSIBLAST (Altschul et al., 1997). Individual protein datasets were initially aligned using the program CLUSTAL w v1.7 (Thompson et al., 1994) with default settings. Multiple sequence alignments were further refined manually using the program 
Table 1. Putative GCREs in the C. albicans $A R O 3$ and $A R O 4$ promoters compared to functional GCREs in $S$. cerevisiae gene orthologues

\begin{tabular}{|llll|}
\hline Species & Gene & Position and sequence* & \multicolumn{1}{c|}{ Reference } \\
\hline S. cerevisiae & ARO3 & ${ }^{-180}$ GTGACTAAT $^{-188}$ & Paravicini et al. (1988) \\
C. albicans & ARO4 & ${ }^{-312}$ ATGACTCAA $^{-304}$ & Kunzler et al. (1992) \\
& ARO3 & ${ }^{-181}$ TTGACTAAT $^{-173}$ & Pereira \& Livi (1993) \\
& & ${ }^{-332}$ CTGACTAAT $^{-324}$ & Pereira \& Livi (1993) \\
& ARO4 & ${ }^{-271}$ ATGACTAAA $^{-263}$ & This study \\
& & ${ }^{-301}$ ATGACTGAA $^{-293}$ & This study \\
& ${ }^{-336}$ CGGACTATT $^{-298}$ & This study \\
\hline
\end{tabular}

"Functionality of the $S$. cerevisiae ARO3 and ARO4 GCREs has been confirmed by mutagenesis and in vitro binding studies (Hinnebusch, 1990; Braus, 1991). The S. cerevisiae ARO3 GCRE exists in an inverse orientation.

† GenBank accession number U53216.

SEQLAB of the GCG v10.0 software package (Genetics Computer Group) with reference to the three-dimensional structure of E. coli phenylalanine-regulated AroG (Shumilin et al., 1999). Regions with residues that could not be unambiguously aligned or that contained insertions or deletions were removed from the alignments. Maximum-parsimony analysis was done using the software package PAUP* (Swofford, 1999). The number of minimal trees and their lengths were estimated from 100 replicate random heuristic searches. Confidence limits of branch points were estimated by 1000 bootstrap replications. Neighbour-joining analysis was performed using the programs NEIGHBOR and PROTDIST of the PHYLIP $3.57 \mathrm{c}$ package (Felsenstein, 1993). In PROTDIST, the 'Dayhoff' option was invoked, which estimates the expected amino acid replacements per position between all pairs of sequences based on the Dayhoff 120 substitution matrix (Dayhoff et al., 1972). The programs SEQBOOT and CONSENSE were used to estimate the confidence limits of branching points from 1000 bootstrap replications. The program TREEVIEW (v1.6.1) was used to visualize trees and prepare figures (Page, 1996).

Plasmid constructions. The plasmid pMB-7 (constructed by Dr N. Gow and a kind gift from Dr W. Fonzi, Georgetown University, Washington, DC, USA) contains the C. albicans URA3 gene (1365 bp ScaI-XbaI fragment; Gillum et al., 1984; Losberger \& Erst, 1989) flanked by 1150 bp direct repeat sequences of the Salmonella typhimurium his $G$ gene (Alani et al., 1987; Fonzi \& Irwin, 1993). The C. albicans ARO4 disruption plasmid pMB7 $\triangle$ aro4 was made by first amplifying a portion of ARO4 from the isolated YEp13ARO4 library plasmid using primers $5^{\prime}$-TCTTCAGATCTATCACCGATGGATGTGTTTCTTG-3' and 5'-ATTATGAGCTCGATCTTGATGAATTAGAAATTGA-3' (restriction sites italicized), digesting with BglII and SacI and subcloning into the corresponding sites of pMB-7, resulting in plasmid pMB7ARO43'. The subcloned $573 \mathrm{bp}$ PCR fragment of pMB7ARO43' corresponds to nucleotides 1466 to 2038 of the ARO4 gene (see GenBank U53216). Following sequence verification, a second $639 \mathrm{bp}$ PCR product (corresponding to nucleotides 621 to 1259 of the GenBank sequence) was amplified as above using primers 5'-TTACAGCATGCGTAATGATGACAGATGTATTGT-3' and $5^{\prime}$-TCATAGTCGACTTGGATCGGTACATTTGGCA-3' (restriction sites italicized), digested with SphI and SalI and subcloned into the corresponding sites of pMB7ARO43', resulting in pMB7 $\Delta$ aro4. This plasmid was digested with $S a c I$ and $S p h I$ to liberate a $5 \cdot 2 \mathrm{~kb}$ ARO4 disruption cassette in which a $205 \mathrm{bp}$ portion of the ARO4 coding region (nucleotides 1260 to 1465) was replaced by his $G:: U R A 3:$ : hisG. Plasmid pCaDis-aro4 was constructed by PCR-amplifying a portion of the $5^{\prime}$ coding region of C. albicans ARO4 (nucleotides 367 to 667 of the GenBank sequence) as above using primers $5^{\prime}$-AAAGGATCCTAGTTATTCTTTGTCAAATAA-3' and 5'-AAACTGCAGGTGAATTGAACATGGACCAAC-3' (restriction sites italicized), digesting with Bam $\mathrm{HI}$ and Pst $\mathrm{I}$, and subcloning the resulting DNA fragment into the corresponding sites in pCaDis [Plasmid pCaDis (Care et al., 1999) was kindly provided by P.E. Sudbery, University of Sheffield, UK]. pCaDis-ARO4 was linearized with BplI, which cuts the plasmid uniquely within the ARO4 sequence, prior to transformation of C. albicans.

Transformation of $\boldsymbol{S}$. cerevisiae and C. albicans. Lithium acetate transformation of $S$. cerevisiae and C. albicans was performed according to the methods of Gietz et al. (1992) and Sanglard et al. (1996), respectively.

Northern-blot analysis. Total RNA was extracted from C. albicans strain B311-A with and without histidine starvation (described above). Poly $(\mathrm{A})^{+}$RNA was prepared by oligo-dT affinity chromatography (mRNA purification kit; Boehringer Mannheim). mRNA was fractionated on a $1.5 \%$ denaturing agarose gel in the presence of $2 \cdot 2 \mathrm{M}$ formaldehyde, transferred to nitrocellulose and probed simultaneously with the ${ }^{32} \mathrm{P}$ labelled (random primed) $222 \mathrm{bp}$ PCR-generated fragment used to clone the ARO4 gene (see above) and with an approximately $0.8 \mathrm{~kb}$ cDNA corresponding to the CYP1 gene encoding cytoplasmic cyclophilin (Koser et al., 1990).

Genomic analysis of C. albicans strains. Strains of C. albicans were analysed using whole-yeast cell PCR (Sathe et al., 1991) and by Southern blotting (Southern et al., 1975). Primers used in ARO4 disruption analysis were 5'-ATTGCCAAATGTACCGATCCAAGT-3' and 5'-CAAGAAACACATCCATCGGTGATA-3', which are designed to amplify the $205 \mathrm{bp}$ deletion/insertion site (see above) in ARO4. PCR analysis of Met3p:: ARO4 strains was performed as above using primers 5'-TCCAAGTGTTGTCACTTTCTT-3' (MET3 promoter; nucleotides 5221 to 5242 of pCaDis) and 5'-CATGATAATCACCAAGTCATC-3' (reverse complement of ARO4 nucleotides 728 to 749). PCR screening for the loss of the wildtype ARO4 allele was performed using primers 5'-TCCAAGTGTTGTCACTTTCTT-3' (MET3 promoter; nucleotides 
5221 to 5242 of pCaDis) and 5'-ATTTGTTCAGCAACACTGTCT-3' (reverse complement of nucleotides 1330 to 1350 of $A R O 4$, deleted in the aro $4 \Delta$ : : his 3 allele). Southern blotting was performed by digesting $C$. albicans genomic DNA with BstXI or BstXI and $\mathrm{HpaI}$ overnight and separating on a $0.8 \%$ agarose gel prior to transfer to nitrocellulose and probing. Probes were generated by PCR and correspond to nucleotides 121 to 1611 and nucleotides 1456 to 1912 of ARO4; they were labelled with ${ }^{32} \mathrm{P}$ using the High Prime DNA Labelling Kit (Boehringer Mannheim Biochemicals).

\section{RESULTS AND DISCUSSION}

\section{Cloning and characterization of the C. albicans ARO4 gene}

We previously generated a $222 \mathrm{bp}$ genomic PCR fragment from a homozygous aro3-deletion strain of $C$. albicans, using a degenerate primer based on a conserved $\mathrm{N}$-terminal region of Aro3p (Pereira \& Livi, 1993), plus a degenerate comeback primer encoding a conserved region of the protein that lies within the deleted portion of the gene (Pereira \& Livi, 1996). The nucleotide sequence of this PCR fragment predicts a 74 aa DAHPsynthase-related peptide with strong homology to known Aro3p/Aro4p proteins. A C. albicans genomic YEp13-based plasmid library (Rosenbluh et al., 1985) was screened using the PCR fragment as a probe. One plasmid isolated was found to contain an approximately $8 \mathrm{~kb}$ insert with a $1110 \mathrm{bp}$ ORF predicting a 370 aa protein corresponding to the probe sequence (GenBank accession no. U53216). The 5'-UTR contains three putative GCREs, at positions - 271 (5'-ATGACTAAA-3'), -301 (5'-ATGACTGAA-3') and $-336\left(5^{\prime}\right.$ CGGACTATT-3') (Table 1; see Braus, 1991). The 5 '-UTR also contains a few potential TATAA elements downstream of these sites (Hinnebusch, 1990), whereas the 3'-UTR contains putative transcription termination signals that resemble the consensus TAGT... TAGT ... TTT (Zaret \& Sherman, 1982).

The 370 aa C. albicans protein, herein designated Aro4p, is $57 \cdot 3-62 \cdot 3 \%$ identical $(67 \cdot 1-70 \cdot 9 \%$. similar $)$ to the Aro3p proteins of S. cerevisiae, C. albicans and Schizosaccharomyces pombe. It shows greater sequence conservation $(60 \cdot 0-68 \cdot 0 \%$ identity and $69 \cdot 9-72 \cdot 8 \%$ similarity) to the Aro4p proteins of $S$. cerevisiae and $S \mathrm{ch}$. pombe, suggesting a functional relationship (Fig. 1).

\section{Molecular evolution of the deduced Aro4p protein}

When compared to prokaryotic orthologues, C. albicans Aro4p is more highly diverged, although several residues are conserved between E. coli and yeast DAHP synthases. It should be noted that naming conventions are not consistent with function among bacterial and yeast DAHP synthases. In $S$. cerevisiae, DAHP Aro3p (P14843) is called AroF, but is inhibited by phenylalanine like E. coli AroG (P00886). Meanwhile, S. cerevisiae Aro4p, called AroG (P32449), is inhibited by tyrosine as is E. coli AroF (P00888). There is no evidence in any yeast genome for a biochemical orthologue to E. coli tryptophan-regulated AroH (P00887).

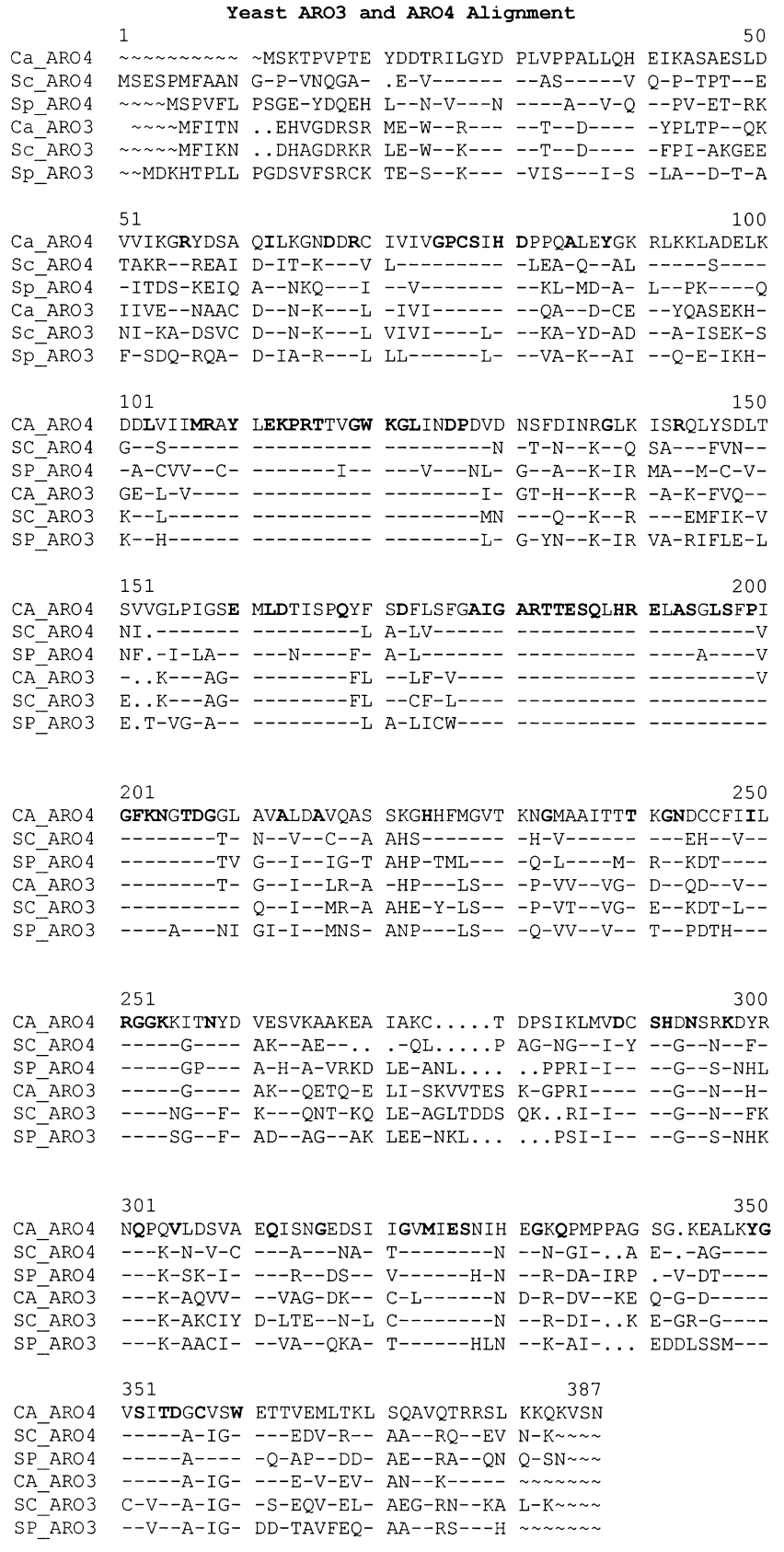

Fig. 1. Deduced amino acid sequence alignment of yeast DAHP synthases. Species are C. albicans (Ca), S. cerevisiae (Sc) and Schizosaccharomyces pombe (Sp). Residues perfectly conserved between the yeast enzymes and also the DAHP synthases in Escherichia coli (AroF, AroG and AroH) are shown in bold. The six proteins (GenPept accession numbers from top to bottom U53216, X61107, AL117210, L12217, X13514, Z54142) were aligned using the PILEUP and PRETTY programs of the Genetics Computer Group sequence analysis software package. Dashes indicate identical amino acid sequences; periods and tildes indicate sequence gaps included to maximize alignments.

Database searches confirmed the existence of three DAHP synthases in the proteobacteria E. coli and Salmonella typhimurium. However, most complete genome sequences of bacteria as well as fungi reveal 


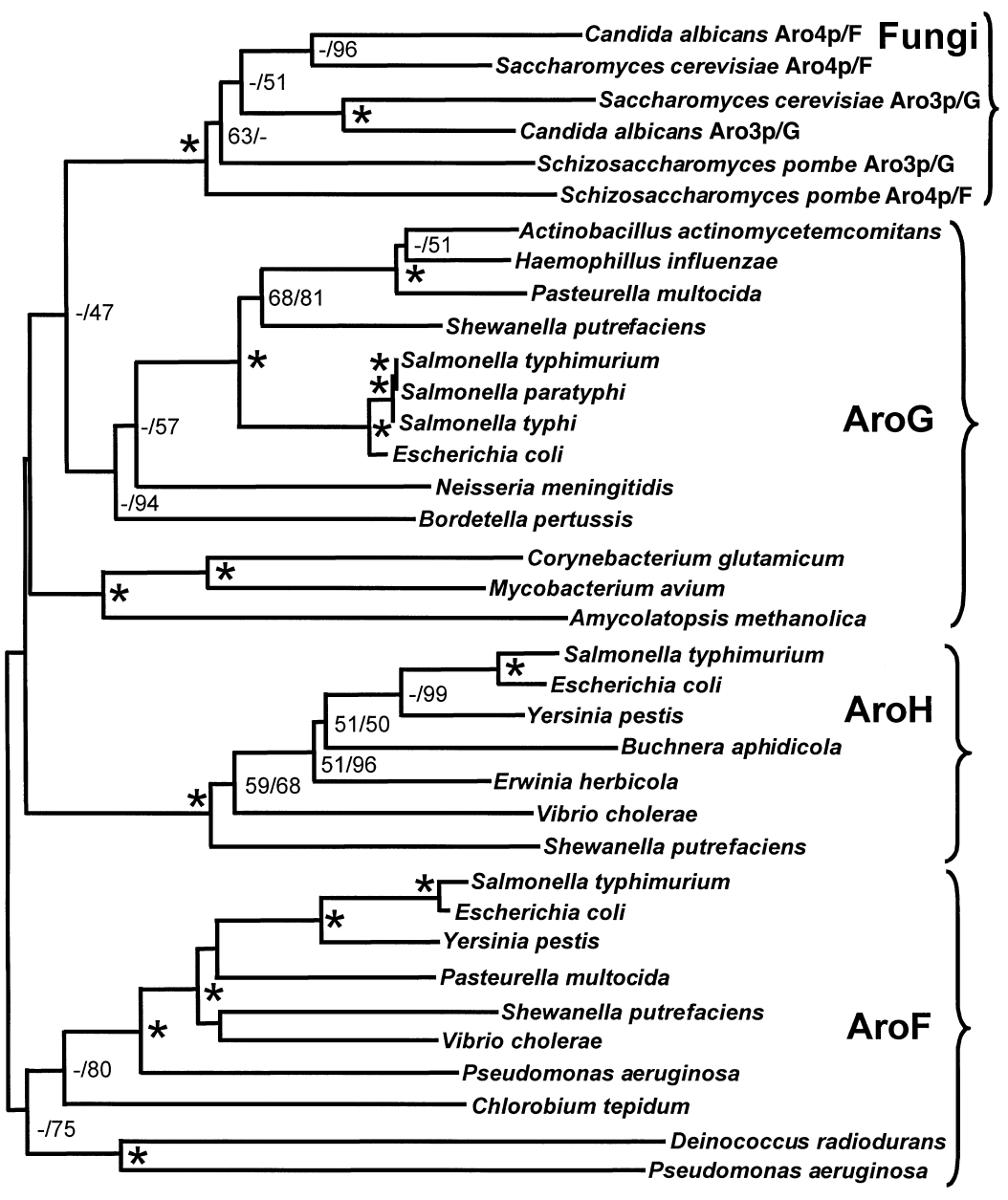

0.1
Fig. 2. Neighbour-joining phylogenetic tree showing convergent evolution of fungal and bacterial DAHP synthases. Phylogenetic tree construction is described in Methods. Numbers along the branches show the percentage occurrence of nodes in 1000 bootstrap replicates of maximum-parsimony and neighbour-joining analyses. Nodes occurring in more than $70 \%$ of resamplings by both methods are marked with an asterisk $\left({ }^{*}\right)$; values less than $50 \%$ are either not shown or indicated as a dash (-). The scale bar represents 0.1 amino acid substitutions per site. In this diagram, we have included the prokaryotic nomenclature after each fungal protein name in order to indicate its functional equivalence (e.g. Aro4p is inhibited by tyrosine as is $E$. coli AroF). fewer than three types of DAHP synthase. For example, the proteobacterium Haemophilus influenzae has only AroG. The sequenced genomes of three fungal species reveal AroG and AroF but not AroH. Thus, the evolution of the different feedback-inhibited types of DAHP synthases appears to be highly species specific.

Generally consistent phylogenetic trees were generated by the maximum-parsimony (MP) and neighbourjoining (NJ) methods. In 100 heuristic searches, MP detected only one shortest tree, which was 2158 steps in length. Phylogenetic analyses show four distinct clusters of DAHP synthases (Fig. 2). The yeast DAHP synthases form one cluster, which is highly divergent from bacterial enzymes. Within the fungal clade, S. cerevisiae and C. albicans Aro3p (AroG-type) and Aro4p (AroFtype) DAHP synthases occurred in clusters specific to each amino acid inhibitor. Although Sch. pombe Aro3p and Aro4p appear to be ancestral to other fungal DAHP synthases, this might be an artifact of their more rapid sequence evolution. Among the bacteria, the three different feedback-inhibited enzymes, AroF, AroG and AroH, formed separate clades. AroG was split into two groups: one consisted of proteobacteria and the other of high-G $+\mathrm{C}$ Gram-positive bacteria (Mycobacterium avium) and actinobacteria (Corynebacterium glutamicum and Amycolatopsis methanolica). While bootstrap and minimal tree search support for five separate clades of DAHP synthases was generally high, the resolution of branching order among the groups was not resolved. NJ provided the best support for clustering the yeast enzymes with bacterial AroG although the bootstrap value $(47 \%)$ was less than $50 \%$. Regardless, phylogenetic analysis suggests that the two different fungal DAHP synthases arose from an early gene duplication in the fungi.

\section{ARO4 mRNA levels increase during amino acid starvation}

To determine whether the C. albicans ARO4 gene is subject to GCN-like transcriptional derepression, we measured the steady-state level of ARO4-specific mRNA in starved and unstarved cells. Starvation was induced with 3-aminotriazole (3AT), an inhibitor of the HIS3 gene product (Hinnebusch \& Fink, 1983). 3AT has been used to induce the GCN response in both $S$. cerevisiae and N. crassa (Ebbole et al., 1991). Northern blot analysis of poly $(\mathrm{A})^{+}$RNA, probed with $C$. albicans ARO4, revealed an increase in abundance of a $1.5 \mathrm{~kb}$ 


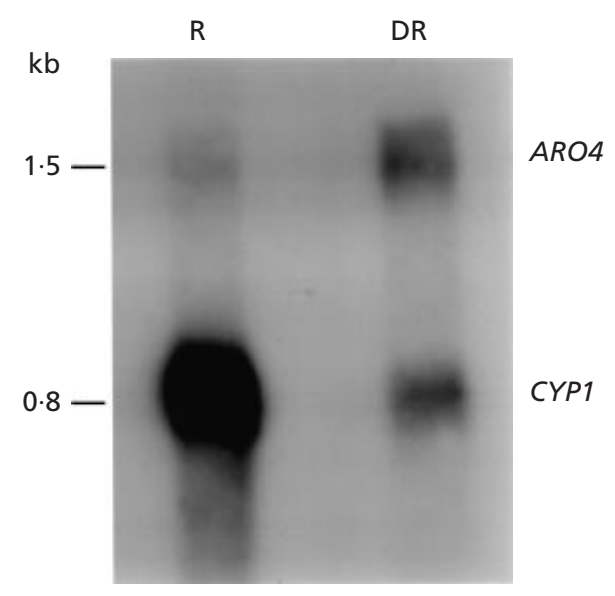

Fig. 3. Northern blot analysis of $A R O 4$ mRNA in unstarved versus histidine-starved cells. Lane 1, cells grown under unstarved, GCN-repressed (R) conditions; lane 2, cells grown under histidine-starved, GCN-derepressed (DR) conditions (addition of $10 \mathrm{mM} 3 \mathrm{AT}$ ). Each lane contains $2 \mu \mathrm{g}$ poly $(\mathrm{A})^{+}$ RNA (quantitated spectrophotometrically). The blot was simultaneously hybridized with ${ }^{32}$ P-labelled ARO4 and CYP1 DNA probes (see Methods). CYP1 encodes cytoplasmic cyclophilin (Koser et al., 1990).

gene-specific transcript in starved (derepressed) cells (Fig. 3). The apparent basal level of ARO4 mRNA in unstarved (repressed) cells is consistent with basal control of ARO4 transcription by GCN4 in S. cerevisiae (Kunzler et al., 1992).

As an internal control for RNA abundance, the blot shown in Fig. 3 was simultaneously probed with a cDNA from the C. albicans CYP1 gene, encoding cytoplasmic cyclophilin, which recognizes an approximately 800 bp mRNA (Koser et al., 1990). The observed reduction in CYP1 mRNA in 3AT-treated cells is consistent with earlier findings, and is probably due to a drop in the overall rate of protein synthesis (Pereira \& Livi, 1995). This result serves to accentuate the observed increase in ARO4-specific mRNA, and our estimates of the derepression ratio compare favourably with those of many starvation-induced genes in S. cerevisiae (data not shown; Hinnebusch, 1990).

\section{Functional expression in S. cerevisiae}

The C. albicans ARO4 gene carried on YEp13 was introduced into $S$. cerevisiae strain RH1368 (aro3-2 aro4-1 gcn1-1 trp1-1 leu2-2), selecting for $\mathrm{Leu}^{+}$transformants. The gcn1-1 mutation renders the cells Gcn4pdeficient, so that functional complementation should correspond to basal gene expression (Hinnebusch, 1990). As shown in Fig. 4(a, b), the C. albicans ARO4 gene, like ARO3 (Pereira \& Livi, 1993), complements the aro 3 aro 4 mutations in $S$. cerevisiae. The ARO3 gene from C. albicans was previously defined by its inability to complement when cells are grown on excess $(2 \mathrm{mM})$ phenylalanine, presumably due to isozyme-specific feedback inhibition (Pereira \& Livi, 1993). Complemen- (a)

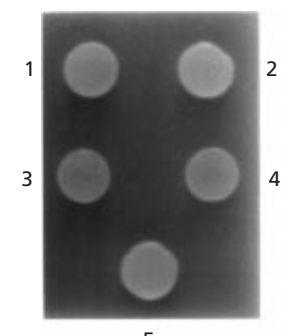

5

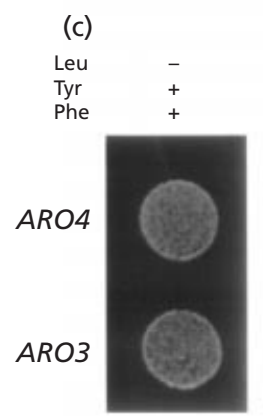

(b)

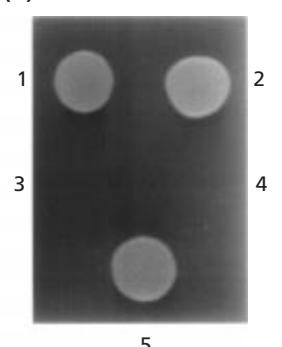

Fig. 4. (a, b) Functional expression of the C. albicans ARO4 gene in $S$. cerevisiae. The high-copy-number yeast episomal plasmid YEp13 (carrying the LEU2 selectable marker) or derivatives thereof containing either the $C$. albicans $A R O 3$ gene (Pereira \& Livi, 1993) or the C. albicans ARO4 gene were introduced into cells of S. cerevisiae strain RH1368 (aro3-2 aro41 gcn1-1 trp1-1 leu2-3), selecting for $\mathrm{Leu}^{+}$transformants. Numbered spots correspond to the following strains in each panel: spot 1, RH1368 plus YEp13-ARO3; spot 2, RH1368 plus YEp13-ARO4; spot 3, RH1368 plus YEp13 alone; spot 4, untransformed RH1368; spot 5, untransformed strain DC17

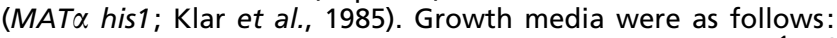
(a) SC (synthetic complete) supplemented with $1 \mu \mathrm{g} \mathrm{ml}^{-1}$ of both thiamin and biotin; (b) SC dropout medium lacking leucine, phenylalanine and tyrosine (SC-Leu-Phe-Tyr). (c) Regulation of $C$. albicans Aro4p activity in $S$. cerevisiae by aromatic amino acids. Cells of S. cerevisiae RH1368 containing either C. albicans ARO3 or C. albicans ARO4 carried on YEp13 were grown in SC dropout media in the presence $(+)$ or absence $(-)$ of the indicated amino acids (supplemented at $0 \cdot 2$ $\mathrm{mM})$ or in the presence of excess $(+++)$ amino acids (supplemented at $5 \mathrm{mM}$ ).

tation by ARO4 was similarly impaired (albeit to a lesser degree) by excess $(5 \mathrm{mM})$ tyrosine (Fig. 4c), but not excess $(5 \mathrm{mM})$ phenylalanine or tryptophan (Fig. $4 \mathrm{c}$ and data not shown). Taken together, these data suggest that C. albicans Aro4p is a structural as well as functional orthologue of S. cerevisiae Aro4p.

\section{Engineering and phenotyping aro4-deficient mutants}

A homozygous aro3-disruption (deletion/insertion) mutant strain of C. albicans (SPC64) (see Table 2 for complete genotypes of all strains) was previously constructed and found to be phenotypically $\mathrm{Aro}^{+}$, suggesting the existence of an additional DAHP synthase isozyme(s) (Pereira \& Livi, 1996). To further investigate the genetic complexity of DAHP synthases in $C$. albicans, we started by sequentially disrupting both 
Table 2. Strains of $C$. albicans and S. cerevisiae

\begin{tabular}{|c|c|c|c|}
\hline C. albicans strain & Parent & Relevant genotype & Reference \\
\hline CAF2-1 & SC5314 & $\Delta u r a 3:: i m m 434 / U R A 3$ & Fonzi \& Irwin (1993) \\
\hline CAI4 & CAF2-1 & $\Delta u r a 3:: i m m 434 / \Delta u r a 3:: i m m 434$ & Fonzi \& Irwin (1993) \\
\hline SPC64 & SPC10 & 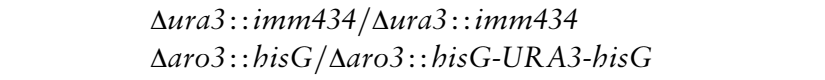 & Pereira \& Livi (1996) \\
\hline SSC1 & CAI4 & $\begin{array}{l}\text { Aura } 3:: \text { imm } 434 / \Delta u r a 3:: i m m 434 \\
\text { Daro } 4: \text { hisG-URA3-hisG/ARO4 }\end{array}$ & This study \\
\hline SSC2 & SSC1 & $\begin{array}{l}\text { Aura3::imm } 434 / \Delta u r a 3:: i m m 434 \\
\text { Aaro4::his } / \text { ARO4 }\end{array}$ & This study \\
\hline SSC2U-23 & SSC2 & 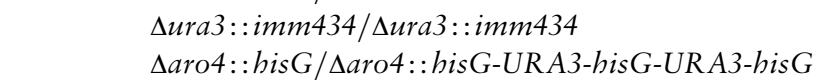 & This study \\
\hline SSC3 & SSC2U-23 & 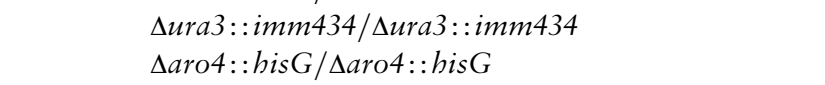 & This study \\
\hline SSC6 & SSC3 & 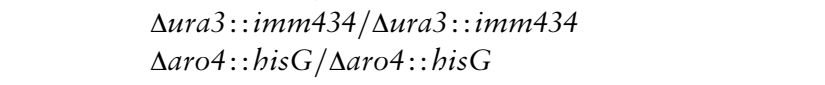 & \\
\hline SSC9 & SSC6 & 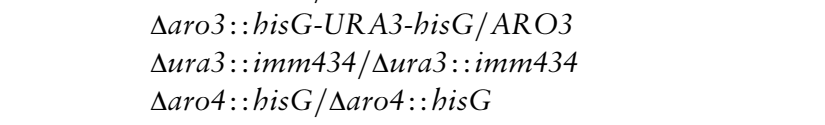 & This study \\
\hline & & $\triangle \operatorname{aro3}::$ hisG/ARO3 & This study \\
\hline SPC101 & SPC64 & 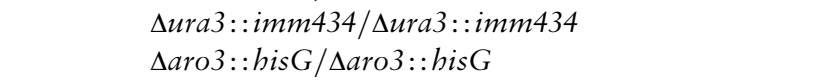 & This study \\
\hline SPC208 & SPC101 & 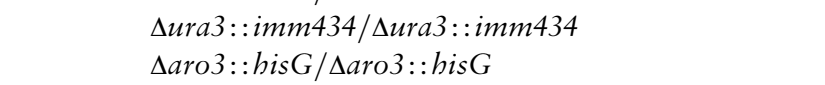 & \\
\hline SPC311 & SPC208 & 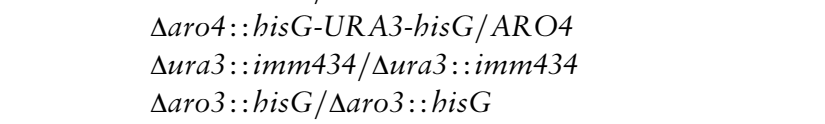 & This study \\
\hline & & $\Delta$ aro $4:$ : hisG/ARO4 & This study \\
\hline SPC311 & SPC208 & 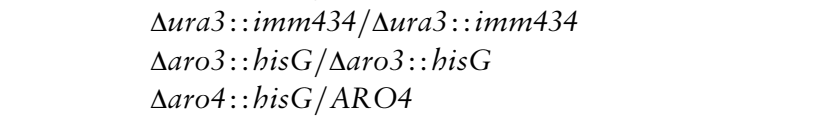 & This study \\
\hline SSC12 & SPC311 & 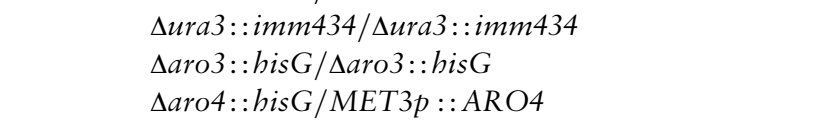 & This study \\
\hline SSC13 & SPC311 & Same as SSC12 & This study \\
\hline S. cerevisiae strain & Genotype & & Reference \\
\hline RH1368 & \multirow{2}{*}{\multicolumn{2}{|c|}{$\begin{array}{l}\text { MAT } \alpha \text { aro3-2 aro4-1 gcn1-1 trp1-1 leu2-3 } \\
\text { MAT } \alpha \text { his1 }\end{array}$}} & Kunzler et al. (1992) \\
\hline DC17 & & & Klar et al. (1985) \\
\hline
\end{tabular}

alleles of ARO4 in strain CAI4, which is wild-type

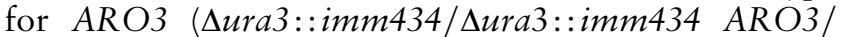
ARO3). This involved the use of an $\triangle$ aro4:: hisG-URA3his $G$ deletion/insertion cassette (see Methods) and the Ura-blaster technique (Alani et al., 1987; Fonzi \& Irwin, 1993), which allows repeated use of the URA3 selectable marker due to homologous intrachromosomal recombination between flanking his $G$ repeats and the generation of $\mathrm{Ura}^{-}$popout mutants.

Briefly, strain CAI4 was transformed with the $5 \cdot 2 \mathrm{~kb}$ SacI-SphI $\Delta$ aro4::hisG-URA3-hisG fragment from plasmid pMB7 4 aro4 and $\mathrm{Ura}^{+}$transformants were selected. Southern blot analysis of genomic DNA digested with BstXI (which cuts outside of ARO4) and probed with an ARO4 PCR product consisting of nucleotides 121 to 1611 (GenBank accession no. U53216), revealed the presence of a second $\sim 9 \mathrm{~kb}$ band in $\mathrm{Ura}^{+}$transformants in addition to the single $5 \mathrm{~kb}$ wild-type ARO4-specific band observed in CAI4 (Fig. 5, lanes 1 and 2). This pattern is indicative of a heterozygous $\Delta$ aro4:: hisG-URA3-hisG/ARO4 genotype. One heterozygote (strain SSC1, Fig. 5, lane 2) was chosen for subsequent experiments. Cells of SSC1 were plated on SC medium plus 5-FOA to select for $\mathrm{Ura}^{-}$ (URA3 popout) mutants. Several $\mathrm{Ura}^{-}$mutants were analysed by genomic Southern as before, and a few appeared to have lost the URA3 gene. One strain, SSC2 (Aaro4:: hisG/ARO4) (Fig. 5, lane 3) was transformed with the same $\Delta$ aro4::hisG-URA3-hisG fragment as before, and $\mathrm{Ura}^{+}$transformants were again selected. Genomic PCR was used to screen the genotypes of 


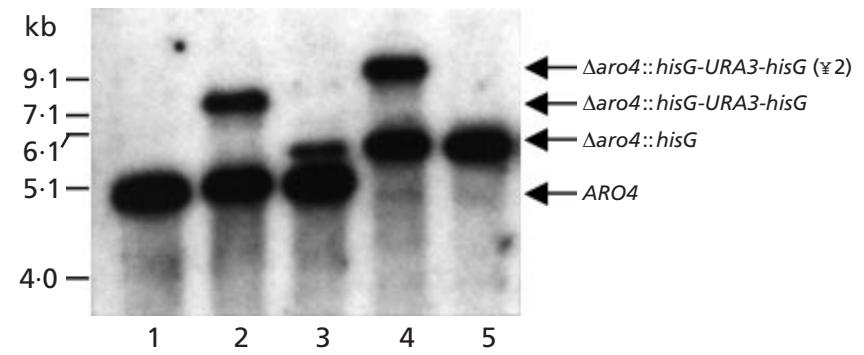

Fig. 5. Southern blot analysis of $C$. albicans aro4 mutants. Genomic DNAs were digested with BstXI and probed with an ARO4-specific PCR product (nucleotides 121-1611). Lane 1, strain CAI4 (ARO4IARO4), which contains a single $5 \mathrm{~kb}$ ARO4specific band; lane 2, strain SSC1 (Daro4::hisG-URA3-

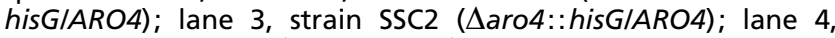
strain SSC2U-23 (Daro4::hisG/Daro4::hisG-URA3-hisG-URA3hisG; duplication of disruption cassette verified by PCR, labelled as $\Delta$ aro4::hisG-URA3-hisG $(\times 2)$ for brevity); lane 5, SSC3

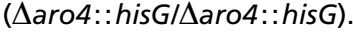

multiple transformants using primers flanking the sequence targeted for deletion. In each individual transformant, the deletion/insertion event occurred at either the wild-type allele or the $\Delta$ aro $4::$ is $G$ allele. A few $\Delta$ aro4:: hisG/Daro4:: hisG-URA3-hisG transformants were identified and analysed by genomic Southern blotting, and one strain, SSC2U-23, was chosen for further study (Fig. 5, lane 4). It was determined that the larger size of the band corresponding to the $\Delta$ aro4: : hisG-URA3-hisG allele in this strain is the result of a duplicative integration event at this allele (verified by PCR; data not shown). Thus, the correct genotype is $\Delta$ aro $4:$ :hisG/Daro4:: hisG-URA3-hisG-URA3-hisG (Table 2). Cells of SSC2U-23 were plated on 5-FOA to select for $\mathrm{Ura}^{-}$popouts, resulting in strain SSC3, which contains two $\Delta a r o 4$ : : hisG alleles (Fig. 5, lane 5).

Both strains containing homozygous null alleles, SSC2U23 and SSC3, retain aromatic amino acid prototrophy (data not shown), presumably due to the presence of functional DAHP synthase activity provided by Aro3p. Growth of C. albicans strains carrying homozygous disruptions of either ARO3 or ARO4 are inhibited by excess tyrosine or phenylalanine, respectively (Fig. 6), indicating specific feedback inhibition of the remaining isozyme. These results suggest that as in S. cerevisiae, only two DAHP synthase isozymes (encoded by ARO3 and ARO4) exist in C. albicans. To demonstrate this more directly, we sought to engineer a homozygous aro3 aro4 double disruption strain.

\section{Attempts to create a homozygous $\Delta$ aro3/ $\Delta$ aro3 $\Delta$ aro4/Daro4 mutant}

The same $\Delta$ aro4::hisG-URA3-hisG deletion/insertion cassette used successfully to disrupt both copies of $A R O 4$ in CaI4 was introduced into an Aro3p-deficient

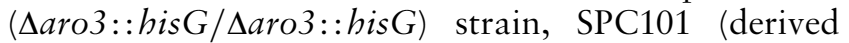
from strain SPC64; Pereira \& Livi, 1996). This re-

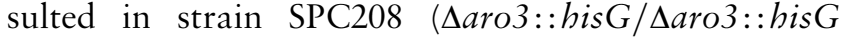
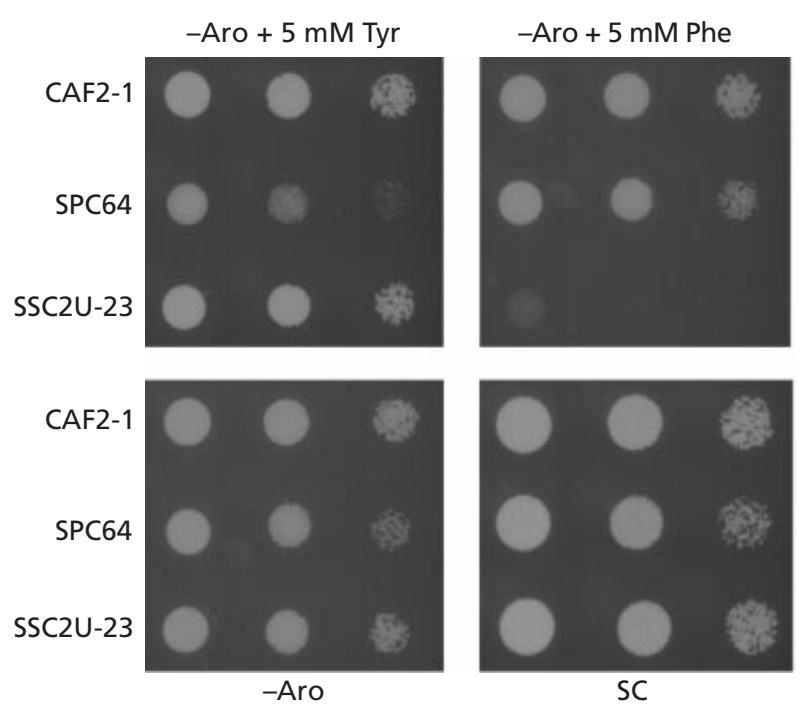

Fig. 6. Effect of feedback inhibition on the growth of $C$. albicans wild-type and aro mutant strains. The panels show growth of C. albicans strains CAF2-1 (ARO3/ARO3 ARO4IARO4), SPC64 (Daro3::hisG/Daro3::hisG-URA3-hisG) and SSC2U-23 (Daro4::hisG/Daro4::hisG-URA3-hisG-URA3-hisG) on SC medium, SC lacking aromatic amino acids, and SC lacking aromatic amino acids to which excess $(5 \mathrm{mM})$ tyrosine or phenylalanine was added.

$\triangle$ aro4:: hisG-URA3-hisG/ARO4), and the subsequent URA3 popout strain (selected on 5-FOA) SPC311

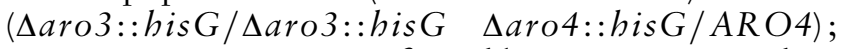
again, genotypes were confirmed by genomic PCR (data not shown) and Southern blotting (Fig. 7b, lanes 2 and $3)$.

The same deletion/insertion cassette was then used to transform strain SPC311 in an attempt to disrupt the remaining wild-type allele of $A R O 4$. Nearly $1000 \mathrm{Ura}^{+}$ transformants were screened by PCR, and in all cases the disruption cassette was found to have integrated either at the previously disrupted $(\Delta a r o 4:: h i s G)$ allele, or at a much lower frequency, at some other site in the genome (data not shown). This type of event may have been favoured over gene replacements at the wild-type allele because of more extensive homology between the his $G$ sequences in the transforming DNA fragment and the $\Delta$ aro $4:$ : his $G$ allele in the chromosome, resulting in more relaxed recombination intermediates, or may be due to recently revealed allele preferences during targeting integration as described by Yesland \& Fonzi (2000).

To address this possibility, three alternative strategies were tried. First, strain SPC311 was transformed with plasmid DNA in which the orientation of the hisGURA3-his G cassette was reversed relative to the flanking $A R O 4$ sequences in plasmid $\mathrm{pMB} 7 \Delta$ aro4, with the intent to reduce the occurrence of double crossover events between the his $G$ repeats of the introduced DNA and the his $G$ of the previously disrupted allele. The second was a nested PCR-based disruption strategy (Wilson et 
(a)
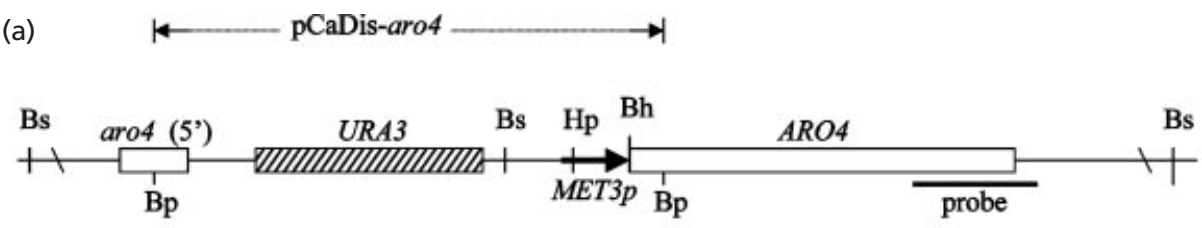

1. MET3p::ARO4 (4kb)

$\uparrow$ pCaDis-aro4 knock-in

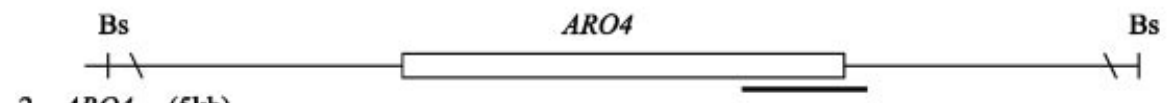

2. $A R O 4(5 \mathrm{~kb})$

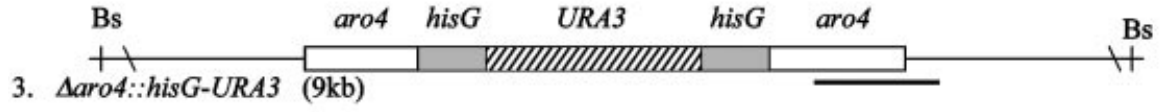

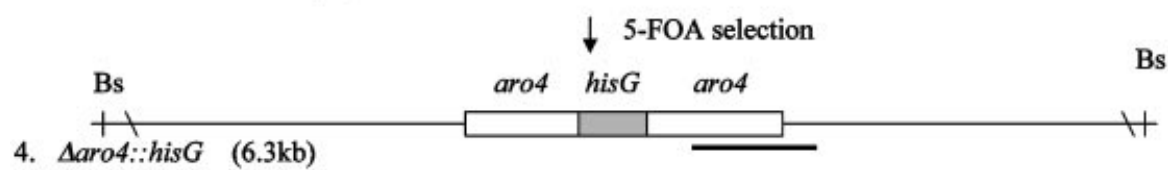

(b)

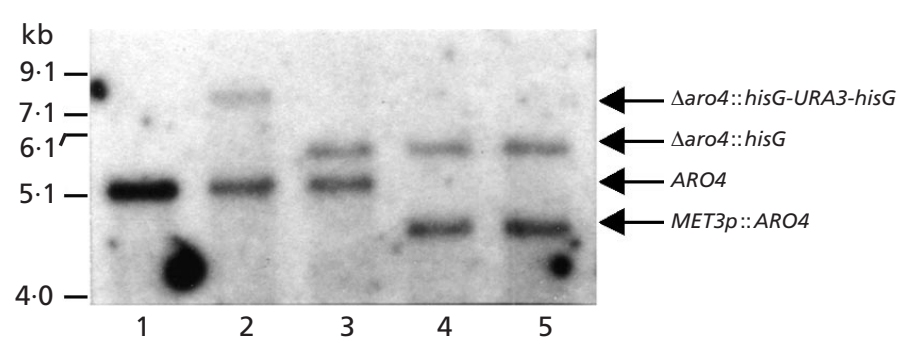

Fig. 7. (a) Schematic showing construction of C. albicans cells lacking Aro3p and Aro4p. Starting with strain SPC101 (ARO4IARO4 $\triangle a r o 3:: h i s G / \Delta a r O 3:: h i s G)$ (line 2), one wild-type ARO4 allele was disrupted via the Ura-blaster technique (Fonzi \& Irwin, 1993) using plasmid pMB7 $\Delta$ aro4 linearized by digestion with Sacl and Sphl. A resulting strain, SPC208, contains one wild-type ARO4 allele (as in line 2) and an $\Delta$ aro4::hisG-URA3-hisG allele (as in line 3). Selection on 5-FOA resulted in loss of the URA3 marker via recombination between the bacterial hisG repeats. One strain, SPC311, was obtained which contains one wild-type ARO4 allele (as in line 2) and an $\triangle a r o 4::$ hisG allele (as in line 4). The remaining wild-type ARO4 allele of strain SPC311 was subsequently placed under the control of the C. albicans MET3 promoter. Plasmid pCaDis-aro4, containing the $5^{\prime}$ coding region of ARO4 (see Methods) was linearized with Bp/l and introduced into cells of SPC311, selecting for Ura ${ }^{+}$transformants. Strain SSC12 contains the $\Delta$ aro4:: hisG allele (as in line 4 ) as well as the MET3p::ARO4 allele (as in line 1). The region of probes used for genomic Southern blotting is indicated by a heavy line, and the expected size of bands hybridizing to the probes is indicated for each allele. Bh, BamHI; Bp, Bp/I; Bs, BstXI; Hp, Hpal; Ps, Pstl. MET3p is the C. albicans MET3 promoter (Care et al., 1999). (b) Genomic Southern blot analysis demonstrating sequential disruption of $A R O 4$ and knock-in of the of MET3 promoter. Genomic DNA from each strain was digested with BstXI and Hpal. The probe was an ARO4 PCR product corresponding to nucleotides 1456 to 1912 . Individual alleles represented by each band are indicated on the right, with positions of size markers on the left. Lane 1, strain CAI4; lane 2, SPC208; lane 3, SPC311; lane 4, SSC12; lane 5, SSC13 (see Table 2 for relevant genotypes).

al., 1999) in which the URA3 marker was amplified using primers containing 90 nucleotides of flanking ARO4 homology. The third strategy was to use the AUR1 dominant selectable marker (Hashida-Okado et al., 1998) to disrupt the final copy of ARO4. None of these strategies produced a strain in which the second ARO4 allele was disrupted. In addition, the medium used to select for double aro4 disruptants in a

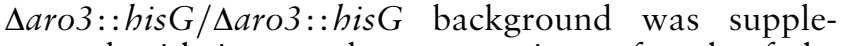
mented with increased concentrations of each of the three aromatic amino acids in an attempt to rescue the potential auxotrophy of the double mutant. Despite these efforts we were unable to generate a disruption of the remaining wild-type copy of ARO4 in strain SPC311. Similarly, we were unable to disrupt the remaining wildtype ARO3 allele in strain SSC9 (Table 2) using the Aaro3:: hisG-URA3-hisG deletion/insertion cassette previously described by Pereira \& Livi (1996) (data not shown).

\section{Construction of an inducible double aro3 aro4 knockout strain}

Recently, a system has been developed that utilizes the promoter of the tightly regulated MET3 gene of C. albicans to assess essentiality and null phenotype of 

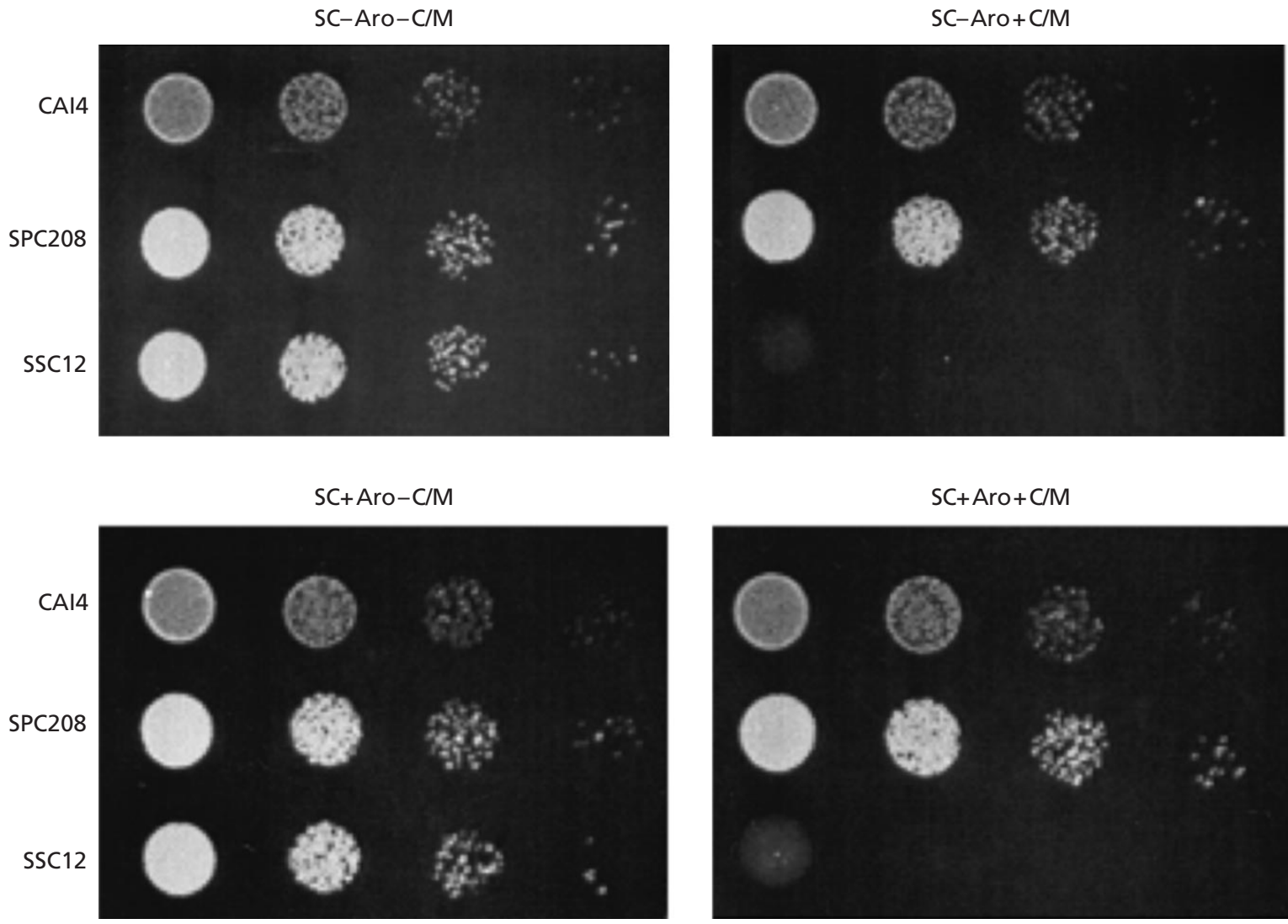

Fig. 8. Effect of switching off $A R O 4$ expression on growth of $C$. albicans. Strains were pregrown for $4 \mathrm{~h}$ in SC liquid medium with or without $0.2 \mathrm{mM}$ aromatic amino acids (SC+Aro or SC-Aro, respectively) and with or without $2.5 \mathrm{mM}$ cysteine (C) and methionine (M). Cell densities were adjusted to $\mathrm{OD}_{600} 0.1$ in the appropriate medium, and 10 -fold serial dilutions were spotted ( $15 \mu \mathrm{l}$ ) onto agar plates containing each medium.

genes in this organism (Care et al., 1999; Warit et al., 2000). The product of the C. albicans MET3 gene is required for the biosynthesis of cysteine and methionine and its expression is strongly repressed in the presence of these amino acids (Care et al., 1999). We constructed an integrating plasmid ( $\mathrm{pCaDis}$-Aro4) in which an extreme $5^{\prime}$ fragment of the ARO4 coding region was placed immediately $3^{\prime}$ of the C. albicans MET3 promoter. Transformation with this plasmid after restriction with $B p l$ within the ARO4 sequence results in a duplicative integration in the genome resulting in a $3^{\prime}$ truncated version of the ARO4 gene as well as a full-length copy under the control of the MET3 promoter (see schematic in Fig. 7a).

We started with strain SPC311 (Aaro3::hisG/ $\Delta$ aro3::hisG $\Delta$ aro4::hisG/ARO4), created using the Ura-blaster technique (as described above). Linearized plasmid pCaDis-Aro4 was introduced into cells of SPC311 and Ura ${ }^{+}$transformants were selected. Transformants were screened by genomic PCR to identify those containing plasmid integrations at the remaining ARO4 locus. A strain with the correct genotype was

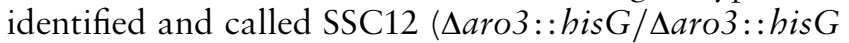
$\Delta$ aro $4:$ hisG/Met3p::ARO4). Proper integration was verified by Southern blotting (Fig. 7b, lane 4). A second isolate with identical genotype was also identified (strain SSC13, Fig. 7b, lane 5).

This strain was tested for growth in the presence or absence of aromatic amino acids under conditions of ARO4 expression or repression (Fig. 8). In the absence of cysteine and methionine and the aromatic amino acids, strain SSC12 grows equally as well as its isogenic parent SPC208, and its progenitor strain CAI4, presumably as a consequence of ARO4 expression. In contrast, strain SSC12 fails to grow in media supplemented with $2.5 \mathrm{mM}$ cysteine and methionine in the absence of the aromatic amino acids tryptophan, tyrosine and phenylalanine. Thus, switching off expression of the last remaining copy of ARO4 results in a conditional growth defect, and both Aro3p and Aro4p are apparently necessary for the growth of C. albicans on synthetic complete medium in the absence of exogenously supplied aromatic amino acids (Fig. 8). Inclusion of the three aromatic amino acids at standard concentrations $(0.2 \mathrm{mM}$ each $)$ did not restore growth to wild-type ARO4 levels (e.g. CAI4 and SPC208), but under these conditions some slow growth of SSC12 was observed (data not shown). Slow growth was also observed on rich (YEPD) medium, presumably due to the presence of some inhibitory levels of cysteine and 

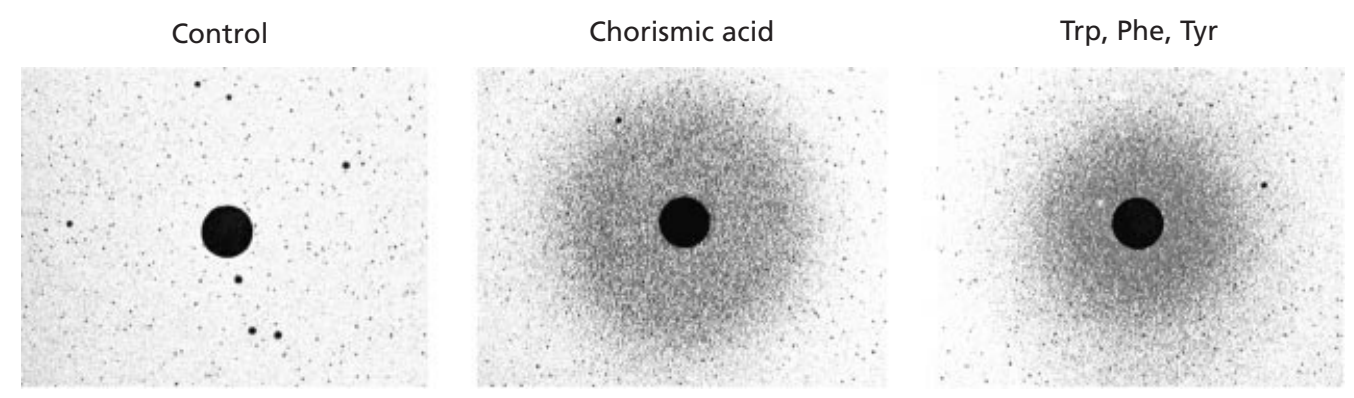

Fig. 9. Filter disc zone-of-growth assays to determine utlization of aromatic amino acids and pathway intermediates. Overnight cultures of C. albicans strain SSC12 were grown in SC-Aro-Cys-Met. Cysteine and methionine were added to $2.5 \mathrm{mM}$ each while the culture was at mid-exponential phase, and the culture was allowed to grow for an additional $4 \mathrm{~h}$. The culture was diluted with SC-Aro $+2.5 \mathrm{mM}$ Cys and Met to $\mathrm{OD}_{600} 0.01$ in $100 \mathrm{ml}$ and poured onto agar plates containing SC-Aro $+2.5 \mathrm{mM}$ Cys and Met medium. Filter discs were soaked in water (control), $45 \mathrm{mM}$ chorismic acid, or a mixture of tryptophan, phenylalanine and tyrosine at $5 \mathrm{mM}$ each. The plates were allowed to grow at $30{ }^{\circ} \mathrm{C}$ for $24-36 \mathrm{~h}$. In contrast to the spot assays shown in Figs 4, 6 and 8, photographs were taken with backlighting, so that the filter disc appears as dark a circle, and zones of growth are indicated by a dark halo of small colonies.

methionine, and was inhibited further with the addition of $2.5 \mathrm{mM}$ each of cysteine and methionine (data not shown).

These data support the idea that, like S. cerevisiae, C. albicans contains two DAHP synthases, Aro3p and Aro4p. However, our results stand in contrast to studies in S. cerevisiae, where disruption of both $A R O 3$ and ARO4 results in aromatic amino acid auxotrophy that can be fully relieved upon supplementation with the appropriate amino acids. To further investigate the nature of the observed phenotype we attempted to rescue the growth defect with higher concentrations of aromatic amino acids as well as several pathway intermediates. We found that the growth defect in strain SSC12 (under conditions where the MET13 promoter is repressed) can be partially rescued in the presence of relatively high concentrations $(5 \mathrm{mM}$ each) of the three aromatic amino acids, or with chorismic acid $(45 \mathrm{mM})$, as illustrated in filter disc zone-of-growth assays (Fig. 9). The zone-of-inhibition format was used because the response was not as easily observed in a spot assay (e.g. as in Fig. 8). Similar results were found with shikimic acid $(100 \mathrm{mM})$ (data not shown). Chorismic acid is the branchpoint intermediate precursor for the synthesis of tryptophan, phenylalanine and tyrosine, as well as $p$ aminobenzoic acid, which is a necessary precursor for folate biosynthesis, whereas shikimic acid occurs upstream of chorismic acid in the pathway.

\section{Concluding remarks}

In contrast to the situation in S. cerevisiae, growth of $C$. albicans engineered to lack DAHP synthase activity is severely inhibited even upon provision of aromatic amino acids. Only a partial restoration of this defect is observed when these amino acids or certain metabolic pathway intermediates are supplied at high concentrations. We conclude that DAHP synthase activity is important for the normal growth of cells under standard laboratory conditions, even in the presence of $0.2 \mathrm{mM}$ aromatic amino acids. A deficiency in amino acid uptake appears unlikely since exogenous tyrosine and phenylalanine were found to cause feedback inhibition in aro3/aro3 and aro4/aro4 strains, respectively (Fig. 6).

In the present study we have demonstrated that cells of C. albicans contain a second, Aro4p-related, DAHP synthase whose expression is coordinately controlled by a GCN-like mechanism and whose activity is sensitive to feedback inhibition by tyrosine. In addition we have shown that in C. albicans, as in S. cerevisiae, Aro3p and Aro4p represent the only functional isozymes of DAHP synthase present in the cell. In contrast to studies in $S$. cerevisiae, however, we have found that when these isozymes are absent, cells growth is severely inhibited even when supplemented with phenylalanine, tyrosine and tryptophan. These results may partially explain our inability to generate a true aro $3 \Delta / \operatorname{aro} 3 \Delta$ aro $4 \Delta / \operatorname{aro} 4 \Delta C$. albicans mutant. Cells devoid of DAHP synthase activity are highly compromised in terms of growth in vitro, but the observed growth defect can be restored to some extent by excess aromatic amino acids as well as certain metabolic intermediates of the aromatic amino acid pathway. The question remains, however, whether this pathway offers tractable targets for development of antifungal drugs. Although it has proven difficult thus far, we are continuing to try to create a true aro $3 \Delta / \operatorname{aro} 3 \Delta$ aro $4 \Delta / \operatorname{aro} 4 \Delta$ mutant under appropriately supplemented growth conditions for use in pathogenicity models for further target validation.

\section{ACKNOWLEDGEMENTS}

We thank Ganesh Sathe for support with DNA sequencing and oligonucleotide synthesis, and Katie Freeman, Douglas DeMarini and Caretha Creasy for helpful discussions.

\section{REFERENCES}

Alani, E., Cao, L. \& Kleckner, N. (1987). A method for gene disruption that allows repeated use of URA3 selection in the construction of multiply disrupted yeast strains. Genetics 116, $541-545$. 
Altschul, S. F., Gish, W., Miller, W., Myers, E. W. \& Lipman, D. J. (1990). Basic local alignment search tool. J Mol Biol 215, 403-410.

Altschul, S. F., Madden, T. L., Schäffer, A. A., Zhang, J., Zhang, Z., Miller, W. \& Lipman, D. J. (1997). Gapped BLAST and PSI-BLAST : a new generation of protein database search programs. Nucleic Acids Res 25, 3389-3402.

Bently, R. (1990). The shikimate pathway - a metabolic tree with many branches. Crit Rev Biochem Mol Biol 25, 307-384.

Braus, G. H. (1991). Aromatic amino acid biosynthesis in the yeast Saccharomyces cerevisiae; a model for the regulation of eukaryotic biosynthetic pathway. Microbiol Rev 55, 349-370.

Care, R. S., Trevethick, J., Binley, K. M. \& Sudbery, P. E. (1999). The MET3 promoter: a new tool for Candida albicans molecular genetics. Mol Microbiol 34, 972-978.

Dayhoff, M. O., Eck, R. V. \& Park, C. M. (1972). A model of evolutionary change in proteins. In Atlas of Protein Sequence and Structure, vol. 5, pp. 89-99. Edited by M. O. Dayhoff. Washington, DC: National Biomedical Research Foundation.

Ebbole, D. J., Paluh, J. L., Plamann, M., Sachs, M. S. \& Yanofsky, C. (1991). $c p c-1$, the general regulatory gene for genes of amino acid biosynthesis in Neurospora crassa, is differentially expressed during the asexual life cycle. Mol Cell Biol 11, 928-934.

Felsenstein, J. (1993). PHYLIP (Phylogeny Inference Package) version 3.57c. Distributed by the author: http:// evolution.genetics.washington.edu/phylip.html, Department of Genetics, University of Washington, Seattle.

Fonzi, W. A \& Irwin, M. Y. (1993). Isogenic strain construction and gene mapping in Candida albicans. Genetics 134, 717-728.

Gietz, D., St Jean, A., Woods, R. A. \& Schiestl, R. H. (1992). Improved method for high-efficiency transformation of intact yeast cells. Nucleic Acids Res 20, 1425.

Gillum, A. M., Tsay, E. Y. \& Kirsch, D. R. (1984). Isolation of the Candida albicans gene for orotidine- $5^{\prime}$-phosphate decarboxylase by complementation of S. cerevisiae ura3 and E. coli pyrF mutations. Mol Gen Genet 198, 179-182.

Hashida-Okado, T., Ogawa, A. \& Takesako, K. (1998). Transformation system for prototrophic industrial yeasts using the AUR1 gene as a dominant selectable marker. FEBS Lett $\mathbf{4 2 5}$, 117-122.

Hicks, J. B. \& Herskowitz, I. (1976). Interconversion of yeast mating types. I. Direct observation of the action of the homothallism (HO) gene. Genetics 83, 245-258.

Hinnebusch, A. G. (1990). Mechanisms of gene regulation in the general control of amino acid biosynthesis in Saccharomyces cerevisiae. Microbiol Rev 52, 248-273.

Hinnebusch, A. G. \& Fink, G. R. (1983). Positive regulation in the general control of Saccharomyces cerevisiae. Proc Natl Acad Sci U S A 80, 5374-5378.

Kirsch, D. R. \& Whitney, R. R. (1991). Pathogenicity of Candida albicans auxotrophic mutants in experimental infections. Infect Immun 59, 3297-3300.

Kishore, G. M. \& Shah, D. M. (1988). Amino acid inhibitors as herbicides. Annu Rev Biochem 57, 627-663.

Klar, A. J. S., Kakar, S. N., Ivy, J. M., Hicks, J. B., Livi, G. P. \& Miglio, L. M. (1985). SUM1, an apparent positive regulator of the cryptic mating-type loci in Saccharomyces cerevisiae. Genetics $111,745-758$.

Koser, P. L., Livi, G. P., Levy, M. A., Rosenberg, M. \& Bergsma, D. J. (1990). A Candida albicans homolog of a human cyclophilin gene encodes a peptidyl-prolyl cis-trans isomerase. Gene 96, 189-195.
Kunzler, M., Paravicini, G., Egli, C. M., Iriger, S. \& Braus, G. (1992). Cloning, primary structure and regulation of the ARO4 gene, encoding the tyrosine-inhibited 3-deoxy-D-arabinoheptulosonate-7-phosphate synthase from Saccharomyces cerevisiae. Gene 113, 67-74.

Losberger, C. \& Ernst, J. F. (1989). Sequence and transcript analysis of the C. albicans URA3 gene encoding orotidine-5'-phosphate decarboxylase. Curr Genet 3, 153-158.

Manning, M., Snoddy, C. B. \& Fromtling, R. A. (1984). Comparative pathogenicity of auxotrophic mutants of Candida albicans. Can J Microbiol 30, 31-35.

Nimmo, G. A. \& Coggins, J. R. (1981). Some kinetic properties of the tryptophan-sensitive 3-deoxy-D-arabinoheptulosonate-7phosphate synthase from Neurospora crassa. Biochem J 199, 657-665.

Page, R. D. M. (1996). TREeVIEW: an application to display phylogenetic trees on personal computers. Comput Appl Biosci 12, 357-358.

Paravicini, G., Braus, G. \& Hutter, R. (1988). Structure of the ARO3 gene of Saccharomyces cerevisiae. Mol Gen Genet 214, 165-169.

Paravicini, G., Mosch, H.-U., Schmidheini, T. \& Braus, G. (1989). The general control activator protein GCN4 is essential for basal ARO3 gene expression in Saccharomyces cerevisiae. Mol Cell Biol 9, 144-151.

Pereira, S. A. \& Livi, G. P. (1993). Cloning and expression of the ARO3 gene encoding DAHP synthase from Candida albicans. Gene 132, 159-165.

Pereira, S. A. \& Livi, G. P. (1995). A GCN-like response in Candida albicans. Cell Biol Int 19, 65-69.

Pereira, S. A. \& Livi, G. P. (1996). Aromatic amino-acid biosynthesis in Candida albicans: identification of the ARO4 gene encoding a second DAHP synthase. Curr Genet 29, 441-445.

Perfect, J. R., Toffaletti, D. L. \& Rude, T. H. (1993). The gene encoding phosphoribosylaminoimidazole carboxylase $(A D E 2)$ is essential for growth of Cryptococcus neoformans in cerebrospinal fluid. Infect Immun 61, 4446-4451.

Rosenbluh, A., Mevarech, M., Koltin, Y. \& Gorman, J. (1985). Isolation of genes from Candida albicans by complementation in Saccharomyces cerevisiae. Mol Gen Genet 200, 500-502.

Sanglard, D., Ischer, F., Monod, M. \& Bille, J. (1996). Susceptibilities of Candida albicans multidrug transporter mutants to various antifungal agents and other metabolic inhibitors. Antimicrob Agents Chemother 40, 2300-2305.

Sathe, G. M., O'Brien, S., McLaughlin, M. M., Watson, F. \& Livi, G. P. (1991). Use of polymerase chain reaction for rapid detection of gene insertions in whole-yeast cells. Nucleic Acids Res 19, 4775 .

Shepherd, M. G. (1985). Pathogenicity of morphological and auxotrophic mutants of Candida albicans in experimental infections. Infect Immun 50, 541-544.

Shumilin, I. A., Kretsinger, R. H. \& Bauerle, R. H. (1999). Crystal structure of phenylalanine-regulated 3-deoxy-D-arabinoheptulosonate-7-phosphate synthase from Escherichia coli. Structure Fold Des 7, 865-875.

Southern, E. M. (1975). Detection of specific sequences among DNA fragments separated by gel electophoresis. J Mol Biol 98, 503-517.

Swofford, D. L. (1999). PAUP*. Phylogenetic Analysis Using Parsimony ("and Other Methods). Version 4. Sunderland, MA: Sinauer Associates.

Teshiba, N., Furter, R., Neiderberger, P., Braus, G., Paravicini, G. \& 
Hutter, R. (1986). Cloning of the ARO3 gene of Saccahromyces cerevisiae and its regulation. Mol Gen Genet 205, 353-357.

Thompson, J. D., Higgin, D. G. \& Gibson, T. J. (1994). Clustal w : improving the sensitivity of progressive multiple sequence alignment through sequence weighting, position-specific gap penalties and weight matrix choice. Nucleic Acids Res 22, 4673-4680.

Warit, S., Zhang, N., Short, A., Walmsley, R. M., Oliver, S. G. \& Stateva, L. I. (2000). Glycosylation deficiency phenotypes resulting from depletion of GDP-mannose pyrophosphorylase in two yeast species. Mol Microbiol 36, 1156-1166.

Wilson, B. R., Davis, D. \& Mitchell, A. P. (1999). Rapid hypothesis testing with Candida albicans through gene disruption with short homology regions. J Bacteriol 181, 1868-1874.

Yesland, K. \& Fonzi, W. A. (2000). Allele-specific gene targeting in Candida albicans results from heterology between alleles. Microbiology 146, 2097-2104.

Zaret, K. S. \& Sherman, F. (1982). DNA sequence required for efficient transcription termination in yeast. Cell 28, 563-573.

Received 9 November 2001; revised 4 December 2001; accepted 7 January 2002. 